\title{
تلوث المياه وأثره على البيئة والانسان من منظور شرعي
}

Doi: 10.23918/ilic2020.31

الاكتور قيس رشيد علي الخزرجي

قسم علوم القرآن الكريم/ كلية التربية للعلوم الإنساتية/ جامعة الموصل

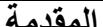

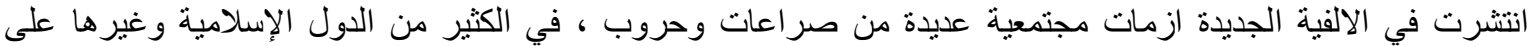

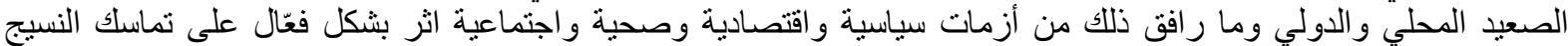

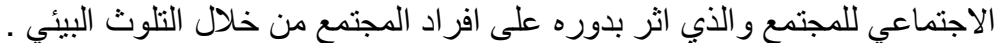

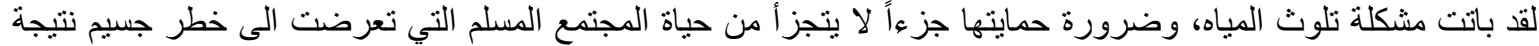

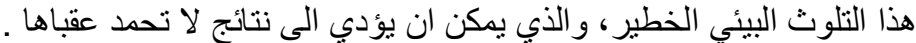

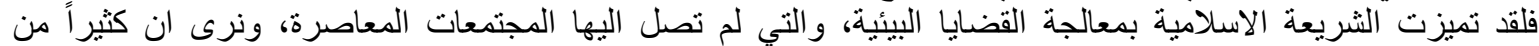

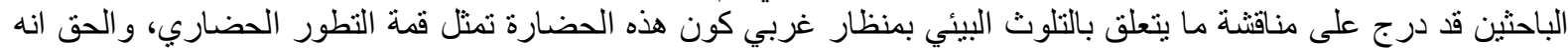

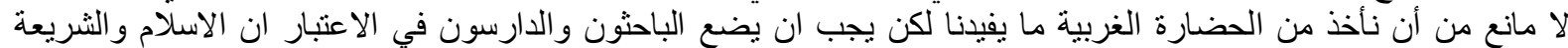

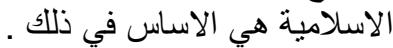

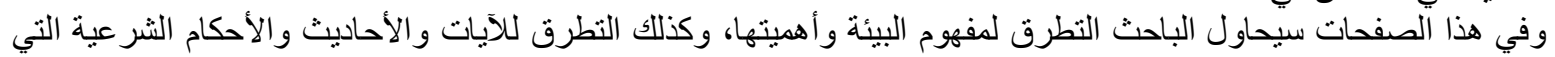

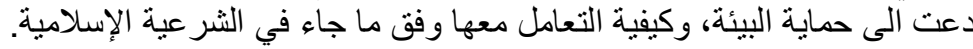

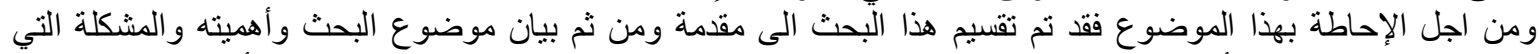

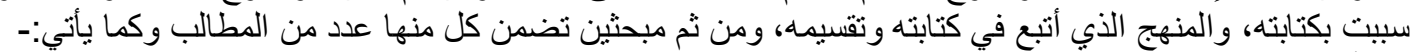

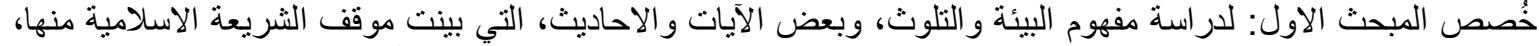

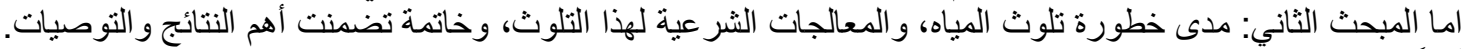

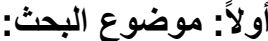

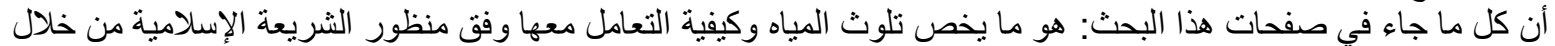

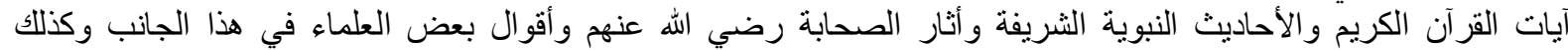

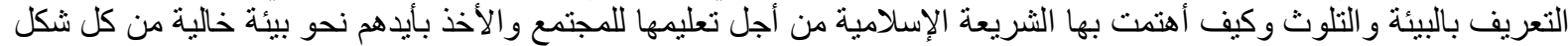
من اشكال التلوث و هذا ما تصبو ألية الثريعة الإسلامية لأبنائها.

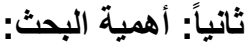

تبرز اهمية هذا البحث من خلاد النية النقاط التالية :-

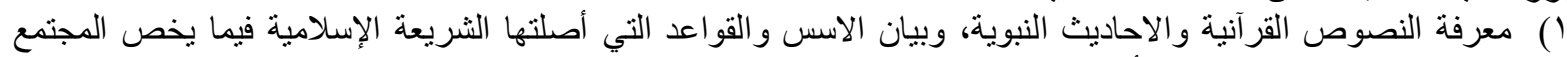

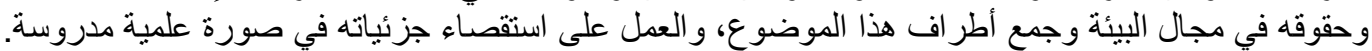

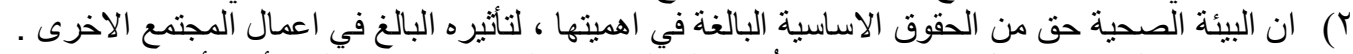

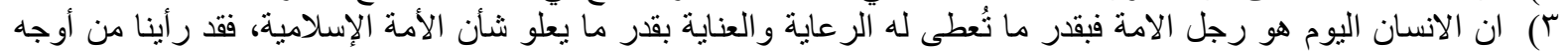

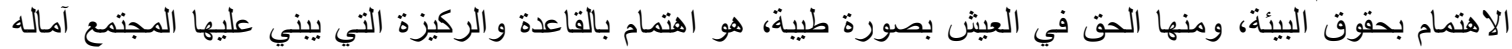
و وغاياته في مجال التقدم.

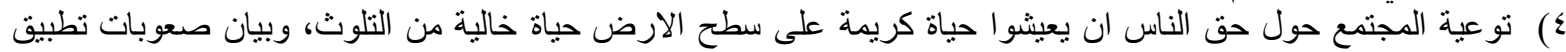

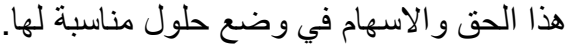

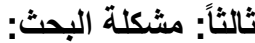
انتشرت في الالفية الجديدة ازمات مجتمعية عديدة من صراعات وحروب ، في الكثير من الدول الإسلامية على الصعيد

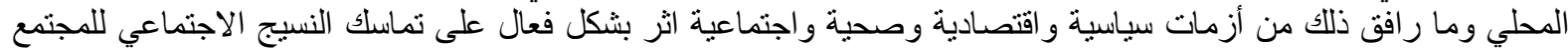

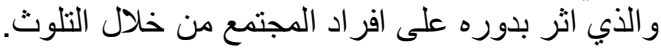

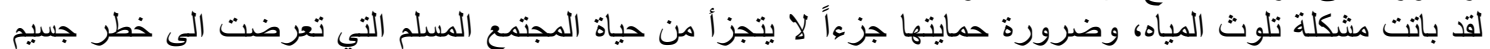

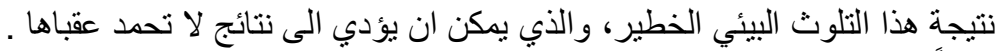
رابعاً: منهج البحث وتقات البئيمه:

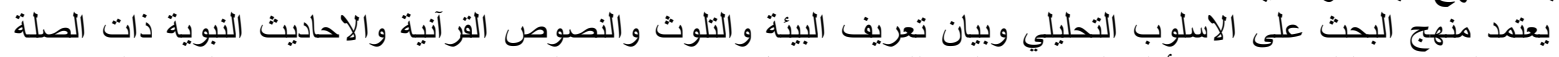

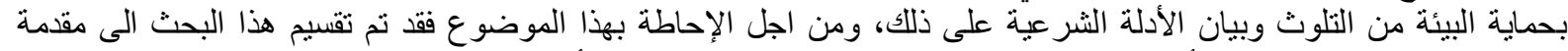

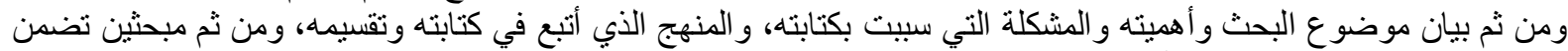

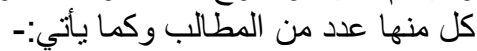

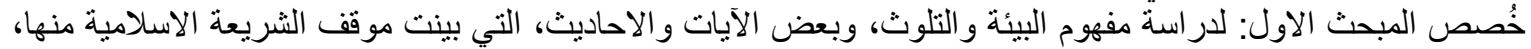

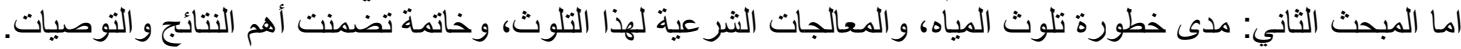




\section{المبحث الاول: مفهوم البيئة والتلوث:

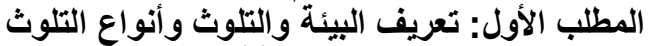

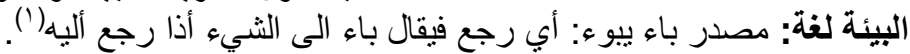

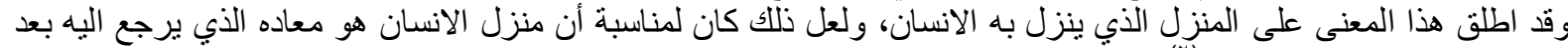

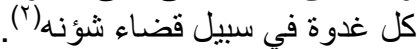

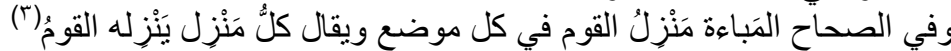

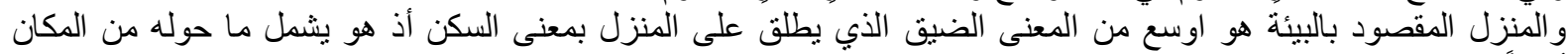

البيئة أصطلاحاً: مصطلح البيئة من المصطلحات المعاصرة فلهذا لم نجد تعريف لها ل عند الفقهاء، فقد اهتم العلماء المحلثون

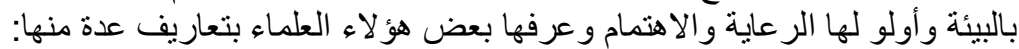

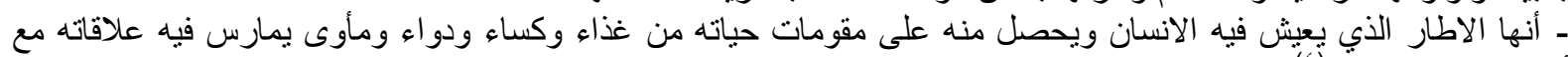

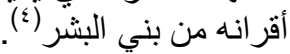

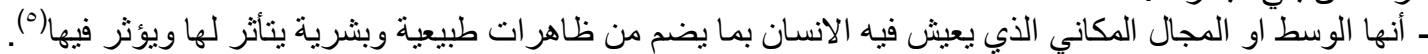

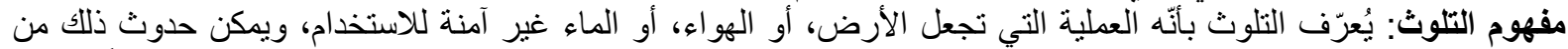

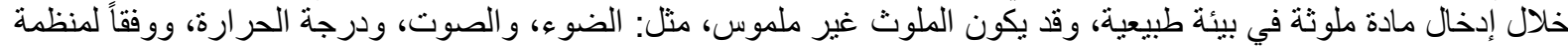

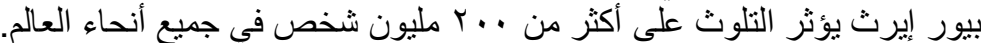

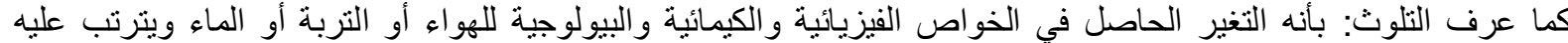

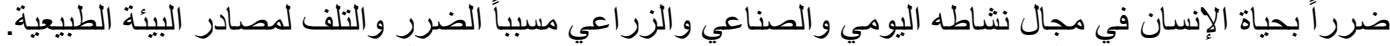

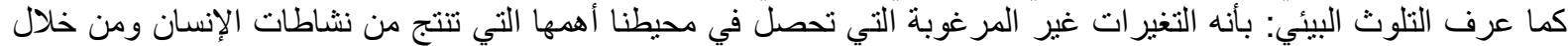

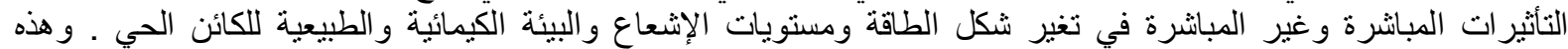

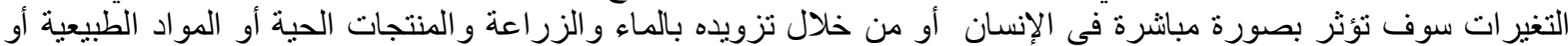

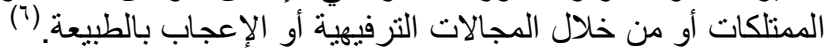

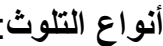

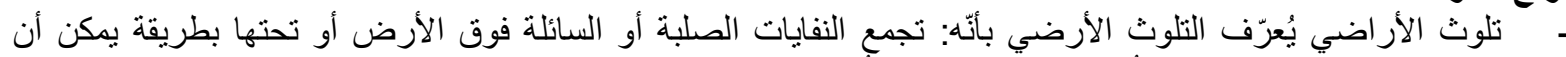

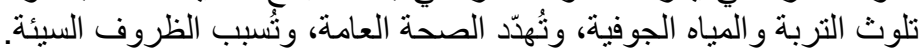

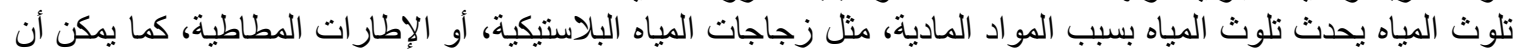

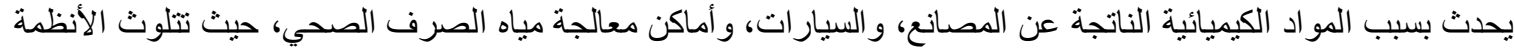

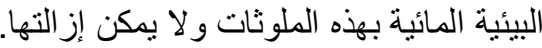

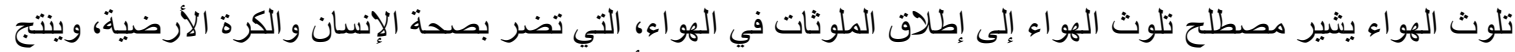

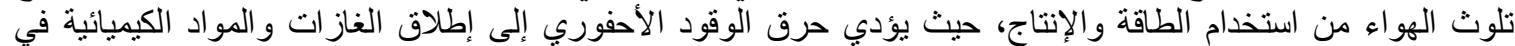

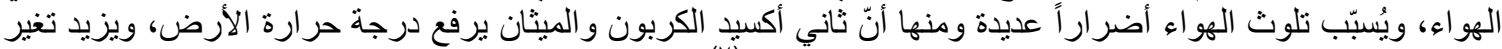

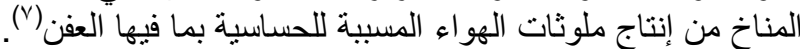

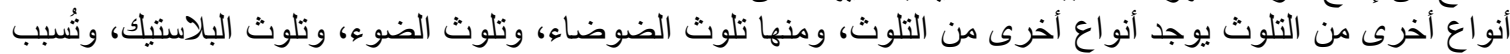
هذه الأنو اعزع القلق للناس.

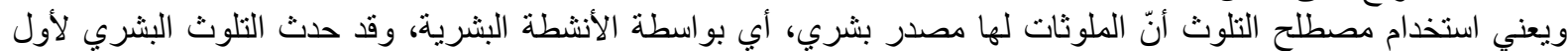

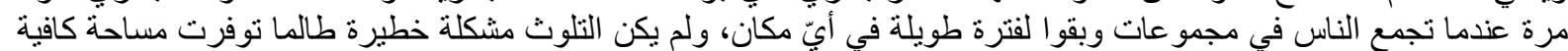

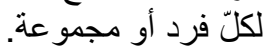

المطلب الثاني: الآيات والاحاديث، التي بينت موقف الثريعة الاسلامية منها.

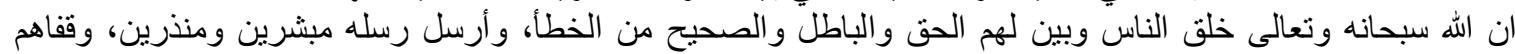

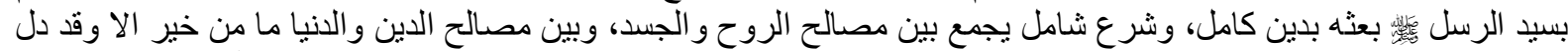

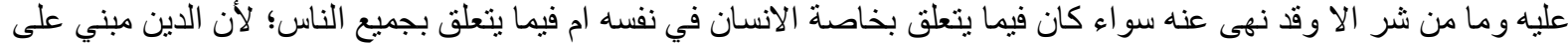

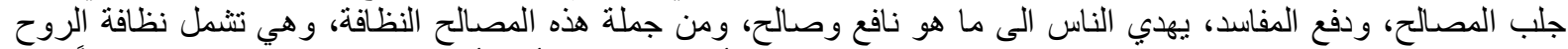

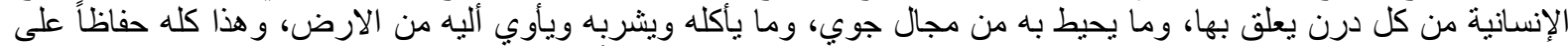

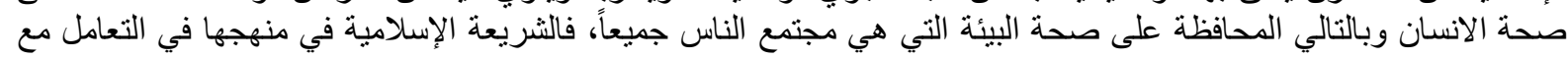

$$
\begin{aligned}
& \text { (') لسان العرب: لأبن منظور : مج، باب الباء: صع^ץ }
\end{aligned}
$$

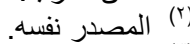

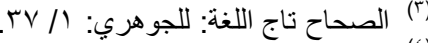

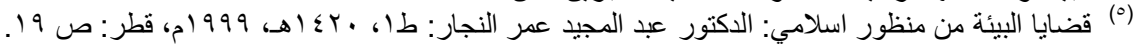

(6) "Pollution Facts \& Types of Pollution", www.livescience.com, Retrieved 16/5/2018. Edited. $\uparrow$ "Land pollution", www.britannica.com, Retrieved 19/6/2018. Edited. $\uparrow$ "Water Pollution: Causes, Effects, and Solutions ", www.thoughtco.com, Retrieved 19/6/2018. Edited. $\uparrow$ "Air

(7) pollution", www.nationalgeographic.org, Retrieved 24-6-2018. Edited. 
جميع نواحي الحياة المختلفة، لم تترك شاردة وواردة في هذه الحباة الا وكان لها الدور البارز والكبير في معالجة كل سلبية من

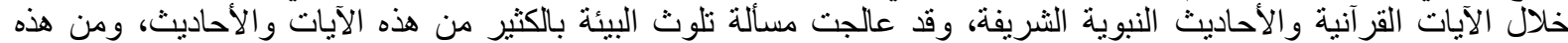
الآيات:

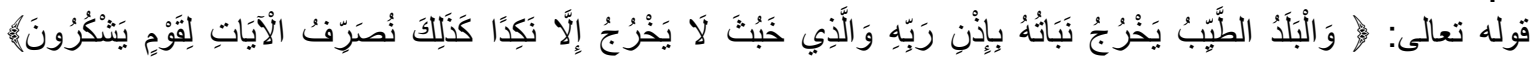

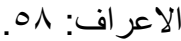

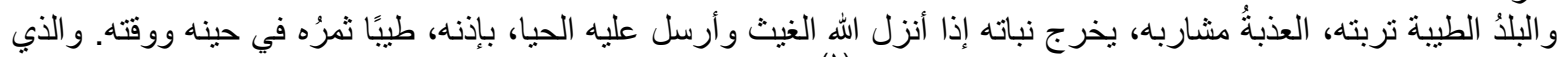

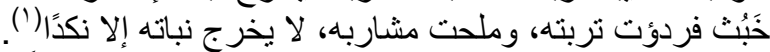

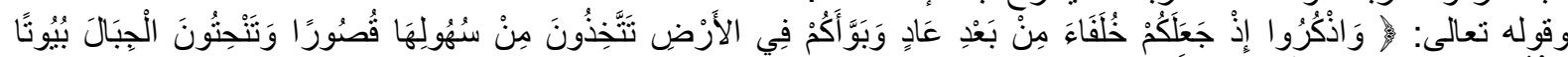

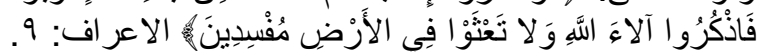

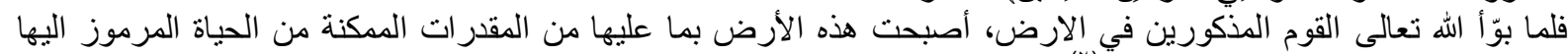

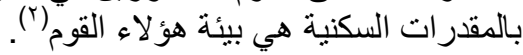

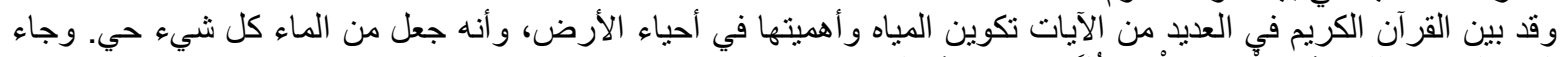

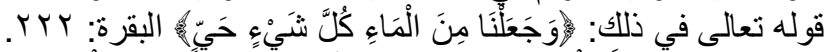

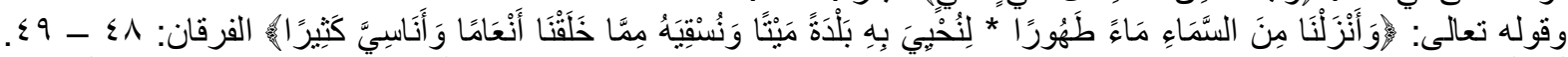

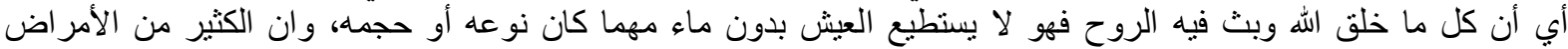

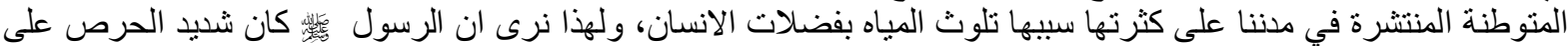

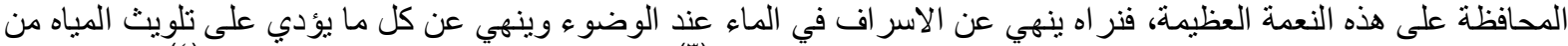

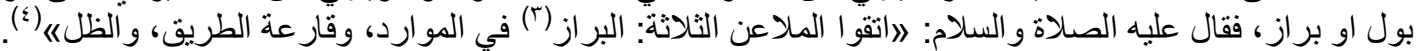

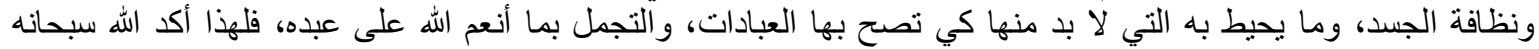

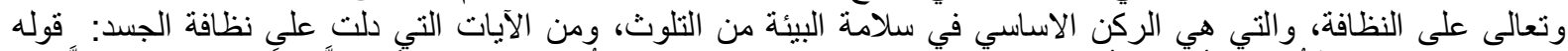

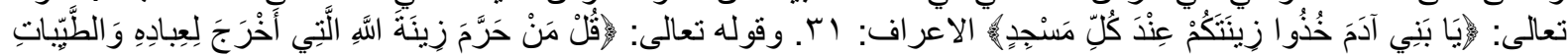

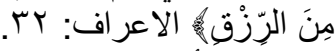

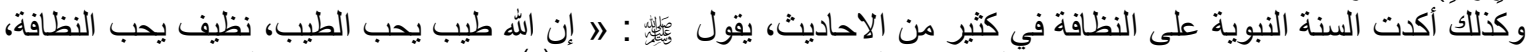

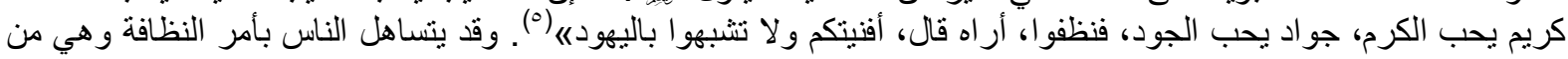
امور دينهم المهمة. بل هي خصلة من خصلة خصال الايمان، فإن الايمان بضع وسبعون شعبة، أعلاها قول لا اله الا الله وادناها اماطة الاذى عن

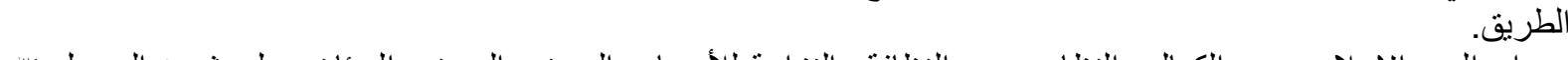

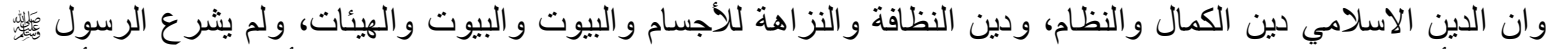

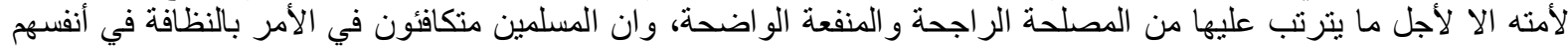
ولقد اهتم الاسلام بمظهر المسلم وزيه، لأنه المرآة التي تعكس صورة المجتمع الاسلامي الفاضل، فتطهير النجاسة من ثوب

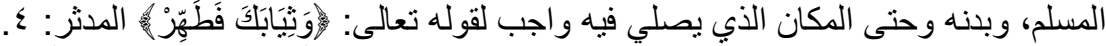

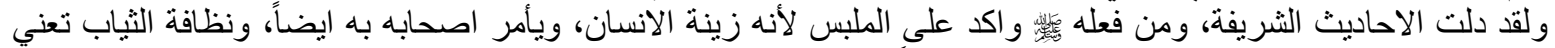

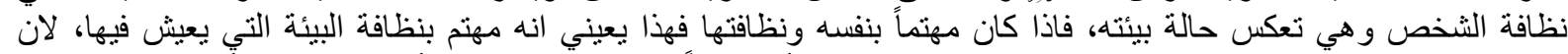

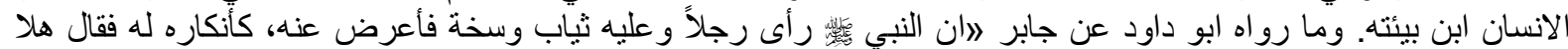

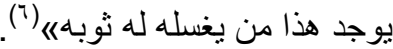

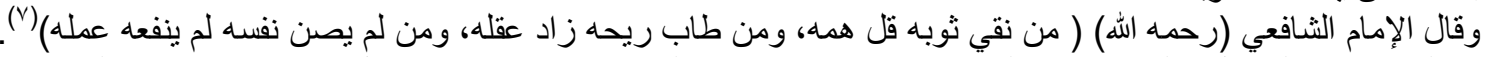

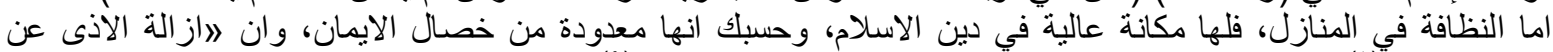

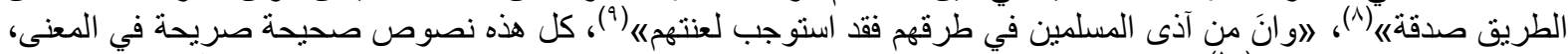

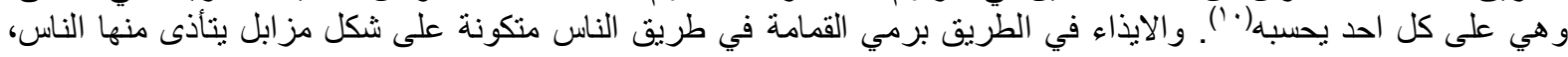

(') جامع البيان في تأويل القرآن: محمد بن جرير بن بزيد بن كثير بن غالب الآملي، أبو جعفر الطبري، تحقق: أحمد محمد شاكر ، مؤسسة الرسالة:

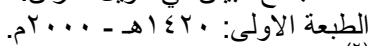

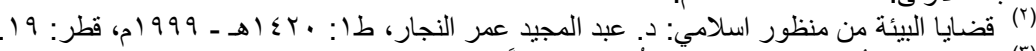

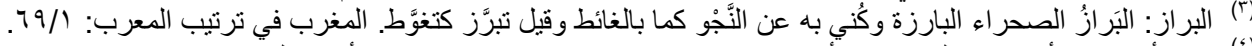

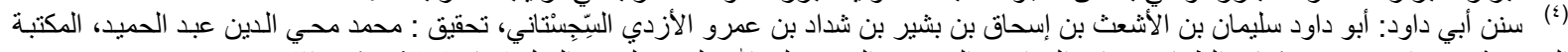

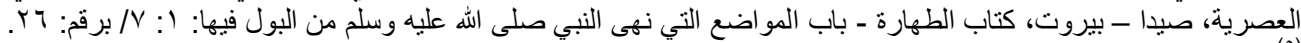

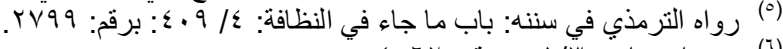

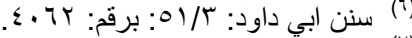

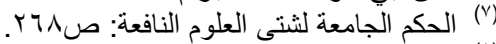

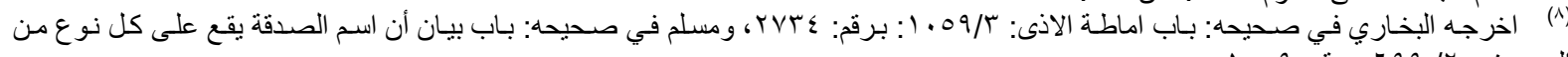

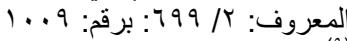

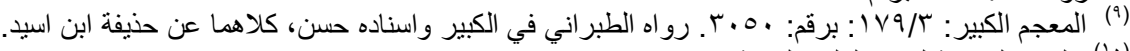

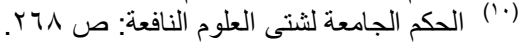




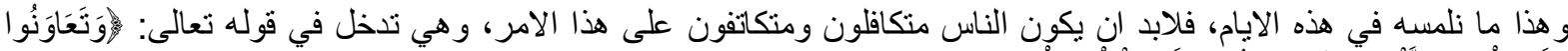

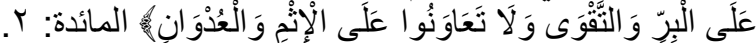

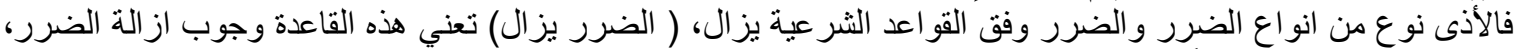

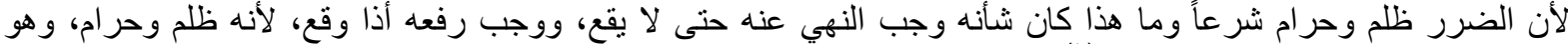

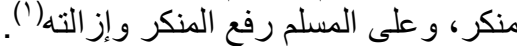

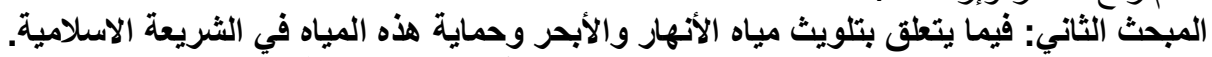

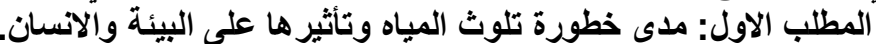

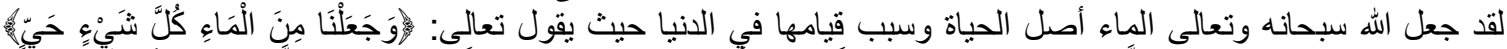

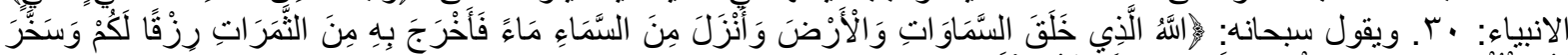

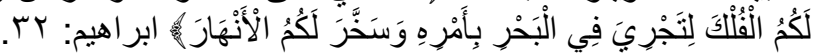

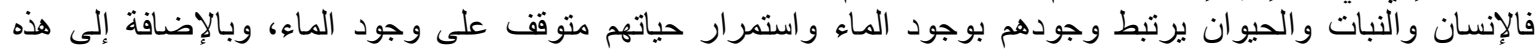

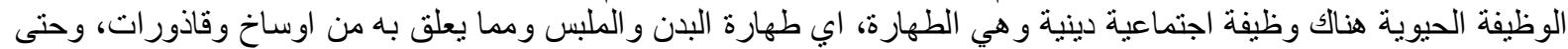

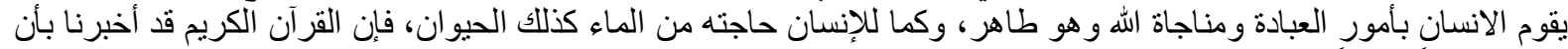

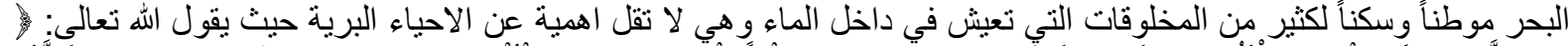

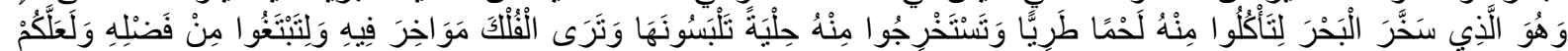

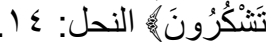

فالمشكلات البيئية الناجمة من تلوث المئية المياه واستنز افها تعد من اخطر المشكلات، و لا غرابة في ذللك فالماء مصدر المياه لكل

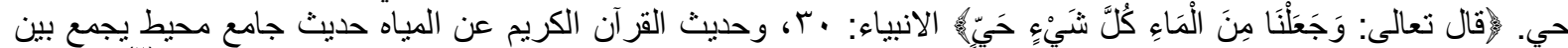

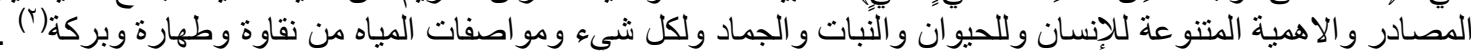

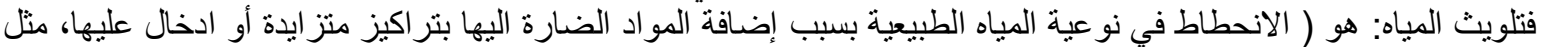

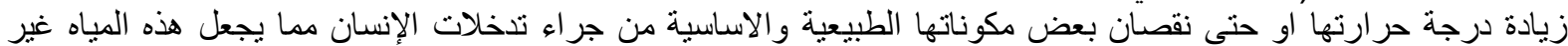

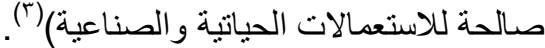

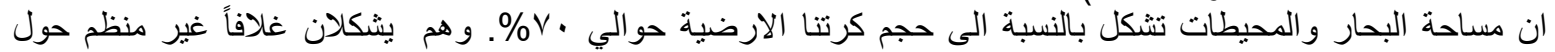

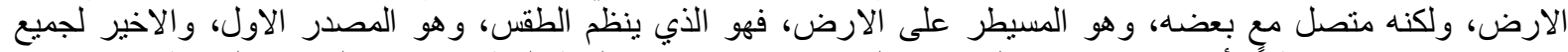

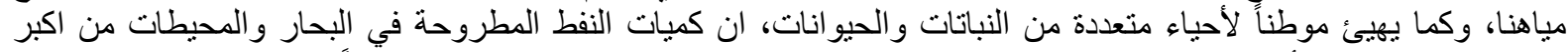

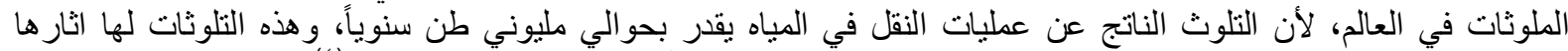

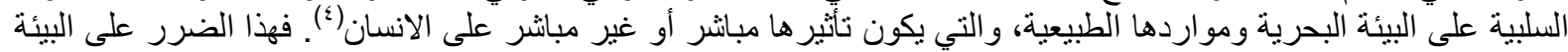

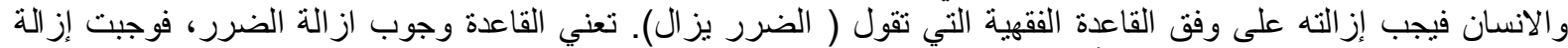

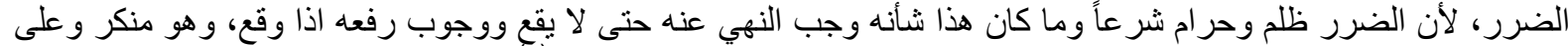

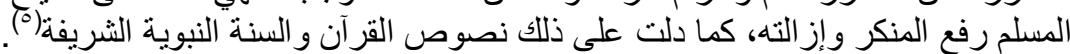

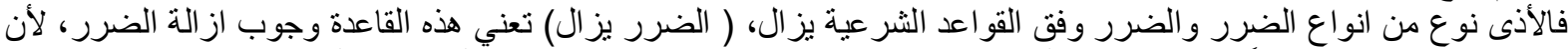

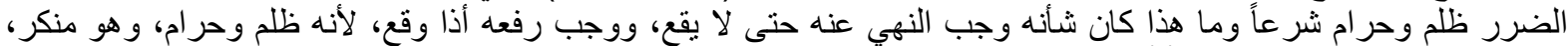

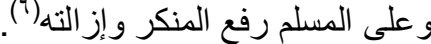

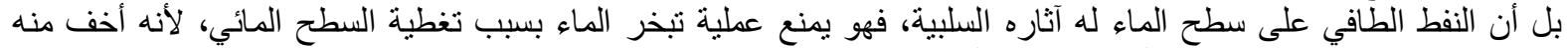

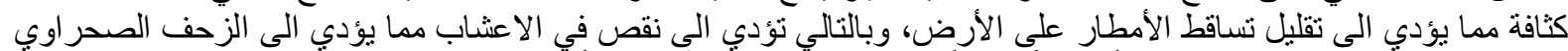

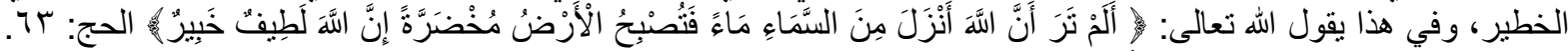

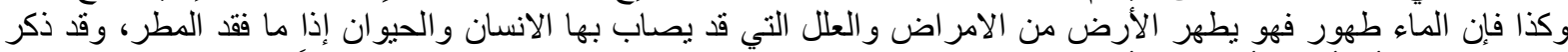

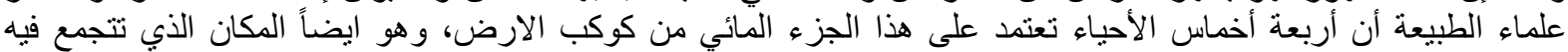

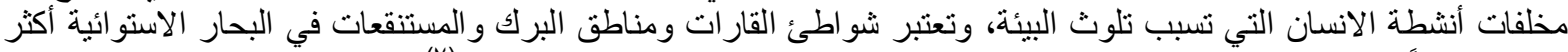

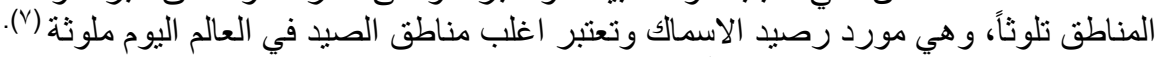

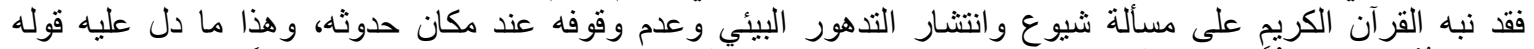

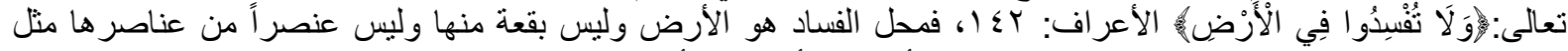

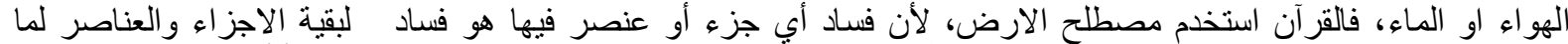

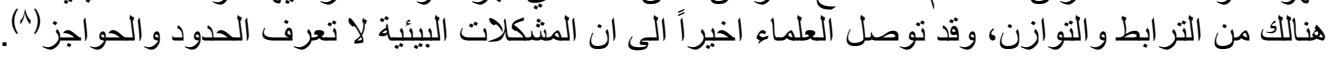

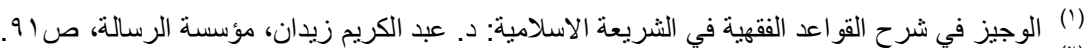

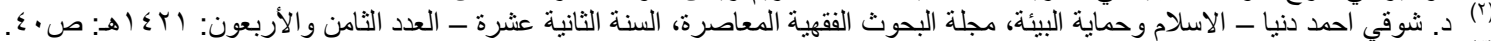

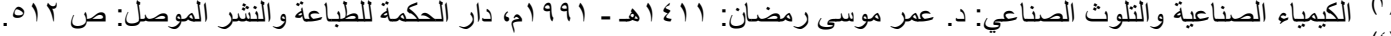

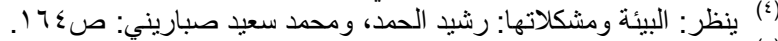

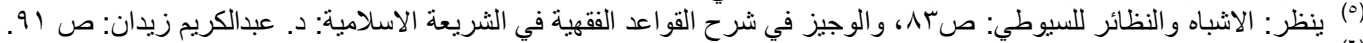

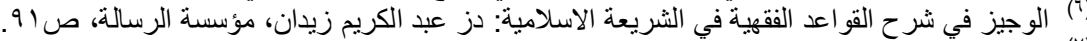

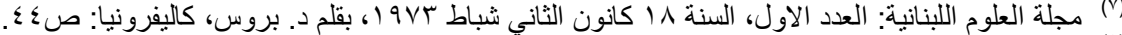

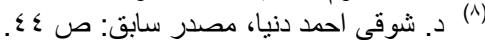


و وذذا التلوث غير المحدود قد أثنار اليه العلم، فإن خطر تلوث البحار بالنفط الخام له تأثير على الحيو انات التي تعيش في الماء،

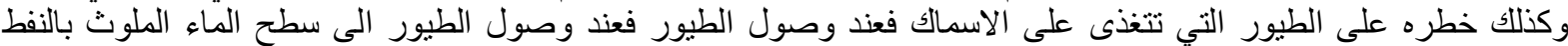

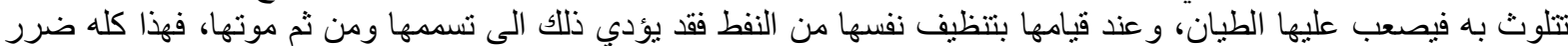

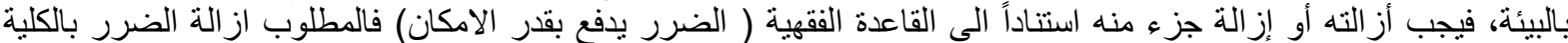

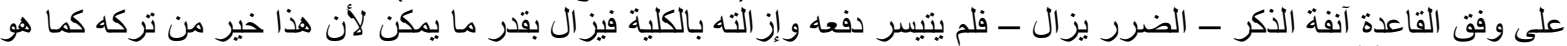

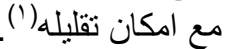
و هناك طرق اخرى لتلويث المياه وهي اثد خطورة من التلوث النفطي، فمياه الأنهار و البحيرات يتم تلويثها عن طريق المئي المياه

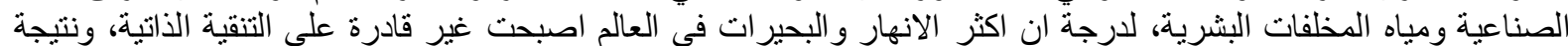

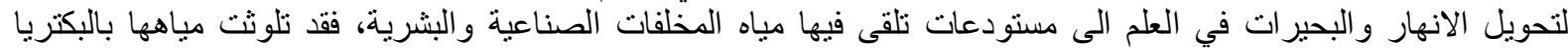

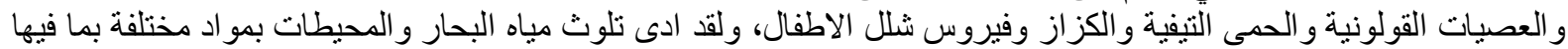

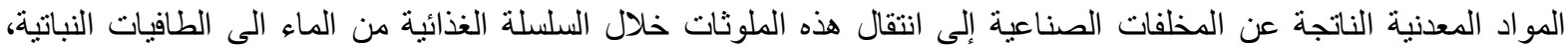

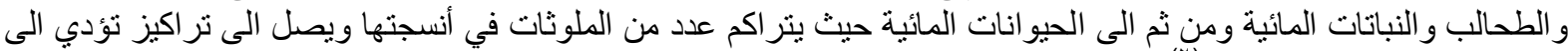

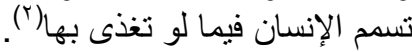

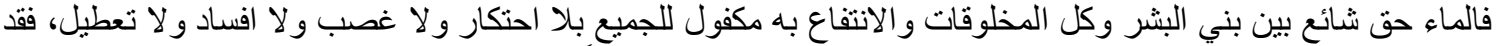

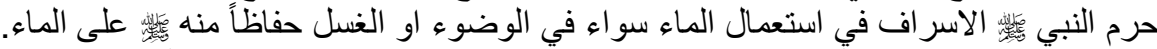

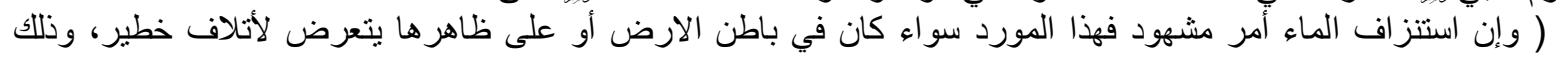

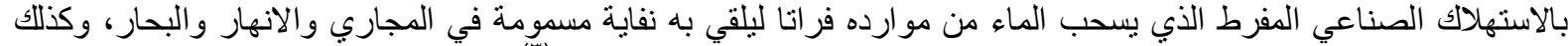

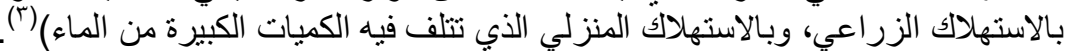

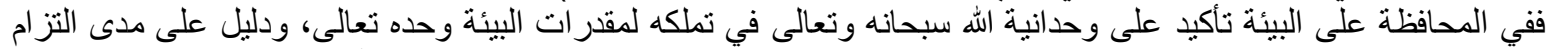

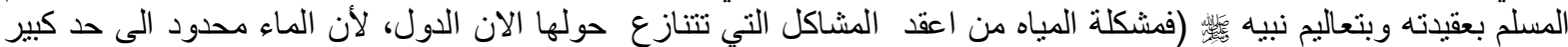
على هذه الكرة الارضية، ومعظم الماء الذي عليها مالح و غير صالح لاستعمال الإنسان لا في الثرب لإن ولان في الصناعة ولاء ولا في

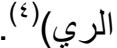

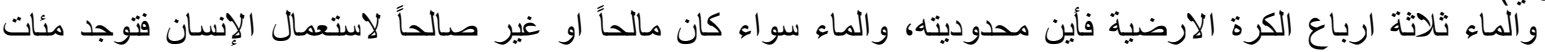

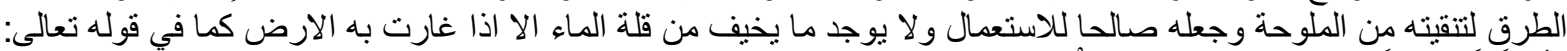

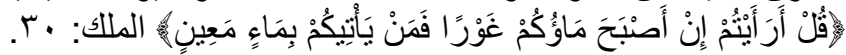

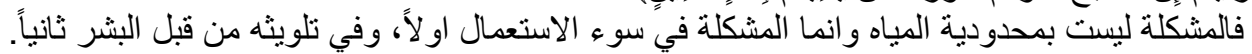

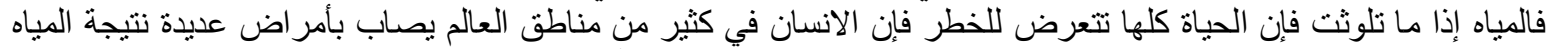

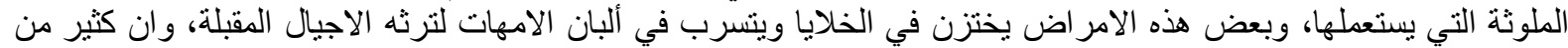

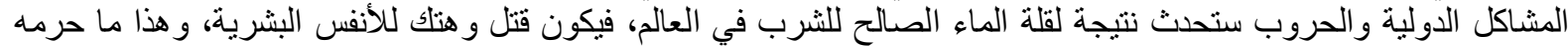

\section{المطلب الثاني: حماية مياه الأنهار والأبحر في الثريعة الإسلامية}

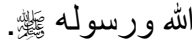

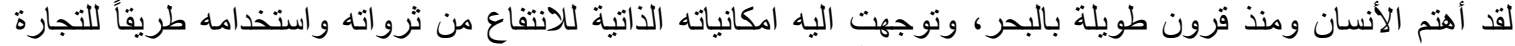

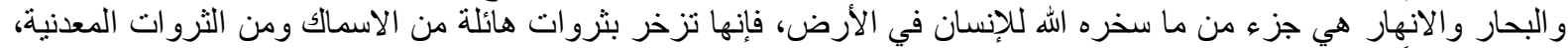

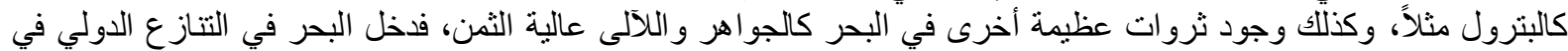

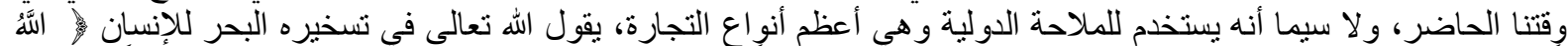

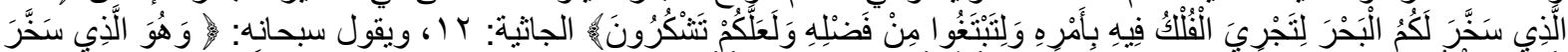

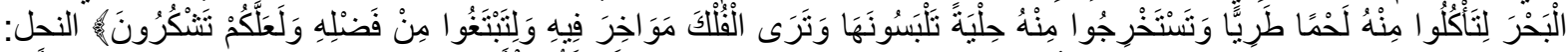

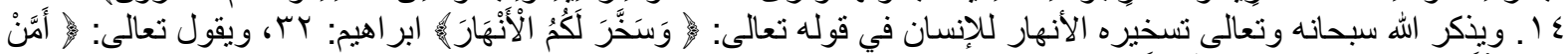

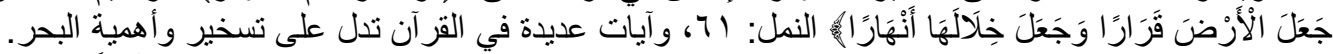

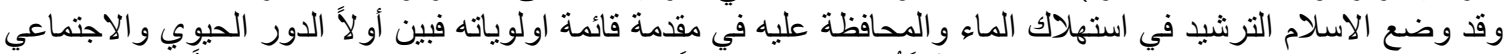

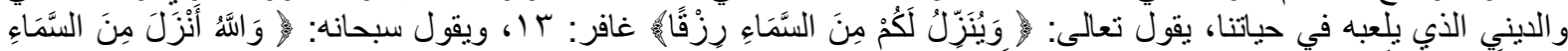

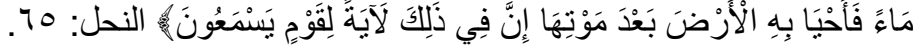

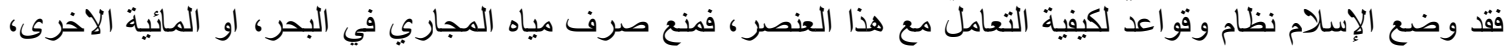

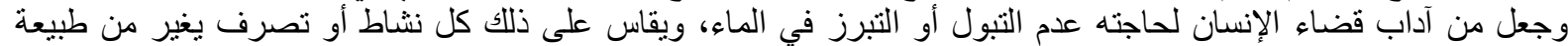

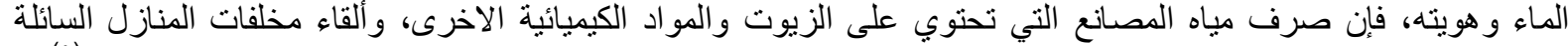

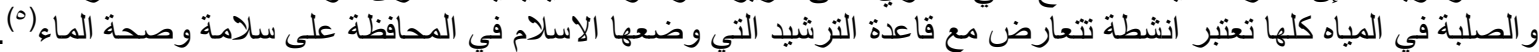

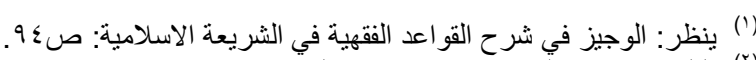

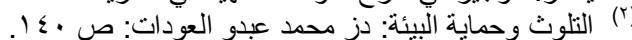

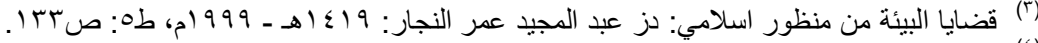

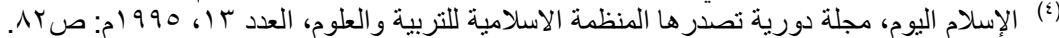

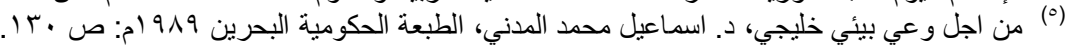




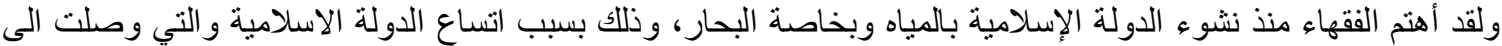

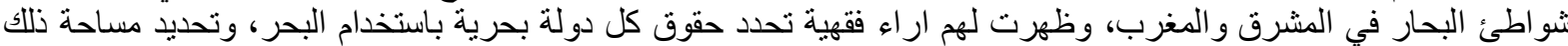

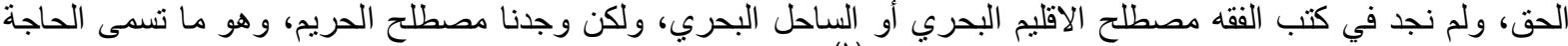

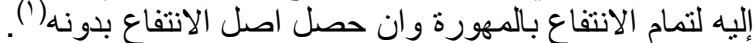

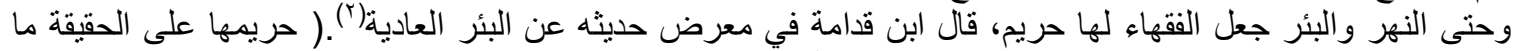

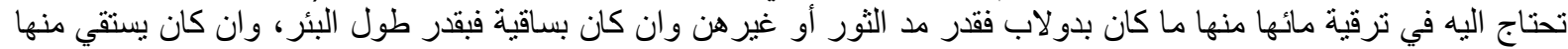

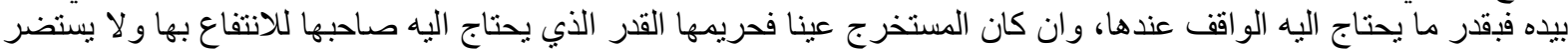

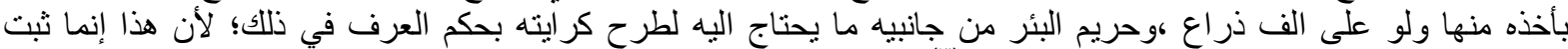

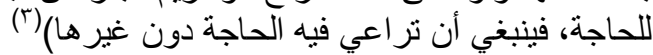

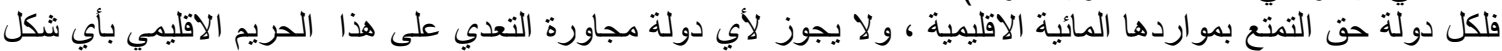

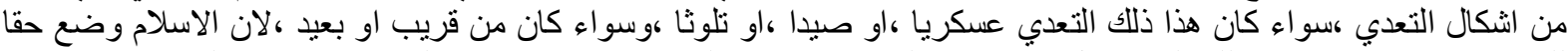

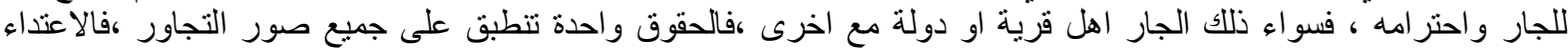

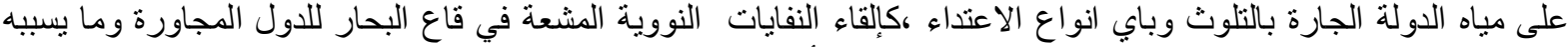

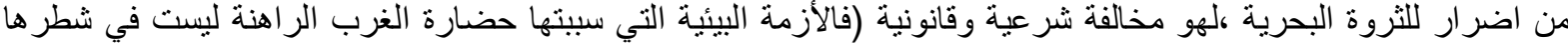

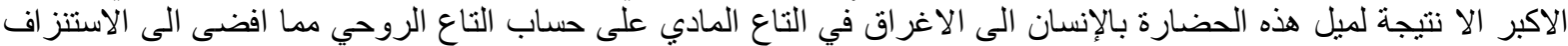

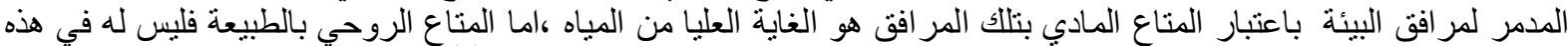

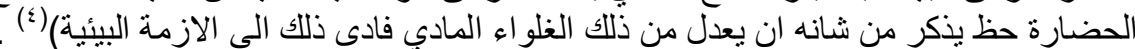

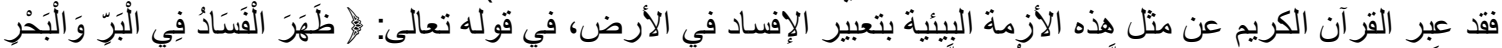

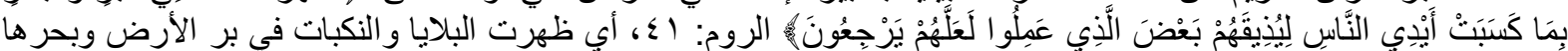

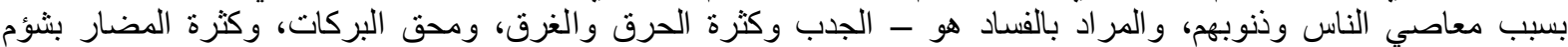

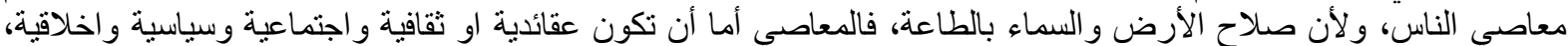

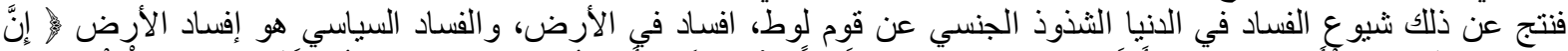

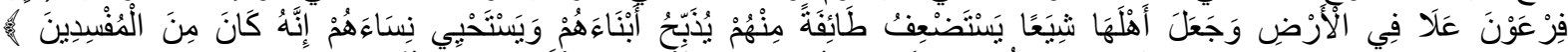

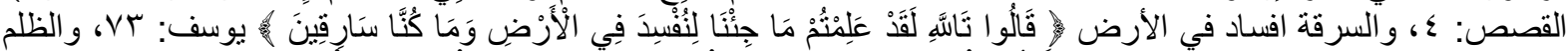

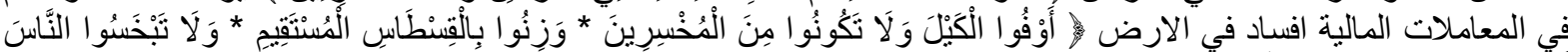

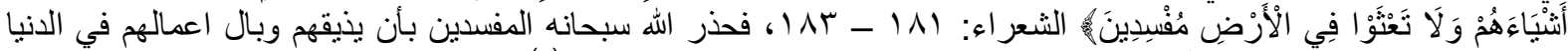

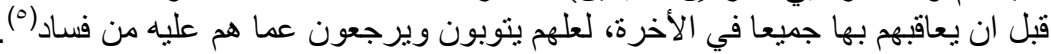

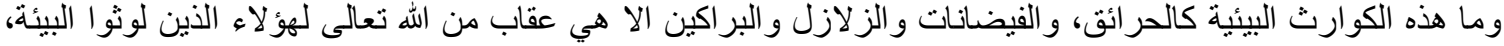

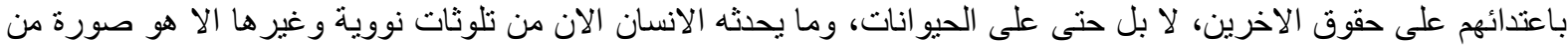
الخاتمة

صور الفساد في البر والبحر.

- ترابط علم الفقه مع علم البيئة، و عدم استغناء علم البيئة عن الفقه، في معالجة قضايا البيئة.

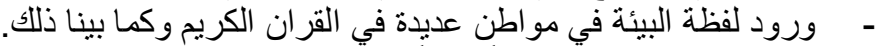

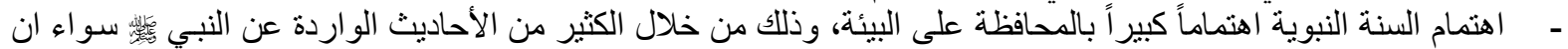
كانت قولية ام فعلية، وكما بينا ذلكا للك.

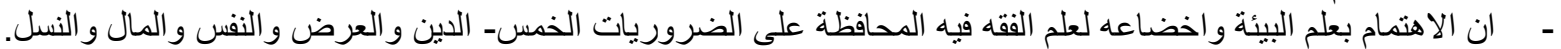

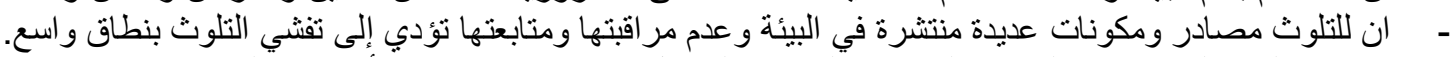

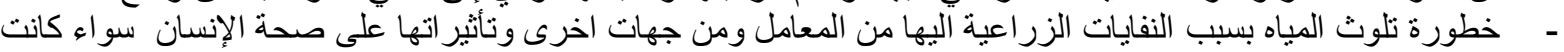
في العراق أو الوطن العربي.

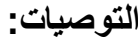

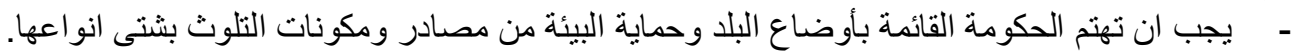

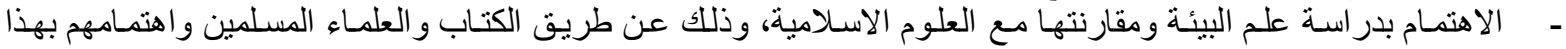
الجانب. - حماية الهو اء من التلوث بمنع ما ينفث من المعامل أولاً وتوقف عملية استخدام الاسلحة الضـارة على البيئة في كافة جهات العالم.

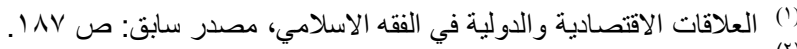

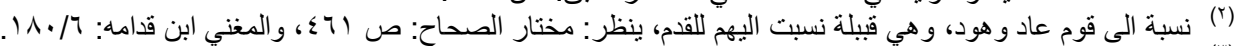

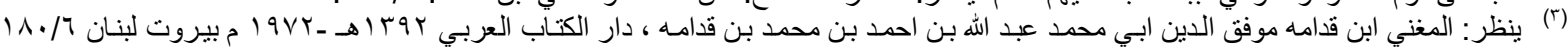


- ـ السبطرة على المياه وحجز الملوثات الاتية من المعامل وعدم السماح لها بالوصول إلى المياه وقيام شبكة انابيب احدث من هذه الانو اع الموجودة المياه والياً واضافة المبات المعقمات.

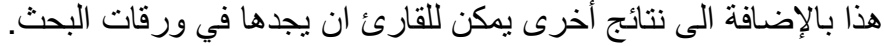
المصادر والمراجع

| (القرآن الكريم.

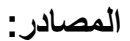

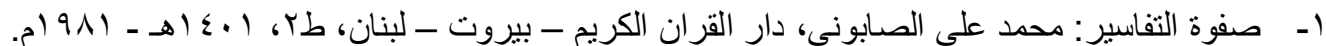

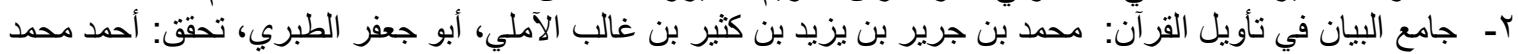

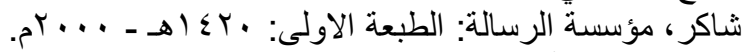

rــ لسان العرب: لأبن منظور، تحقيق: عبد الله علي الكبير + محمد أحمد حسب الله + هاتثم محمد الثاذلي، دار المعارف ـ القاهرة.

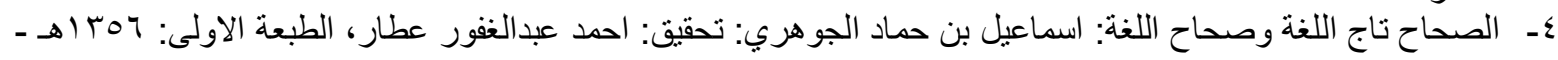
. 1907

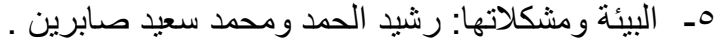

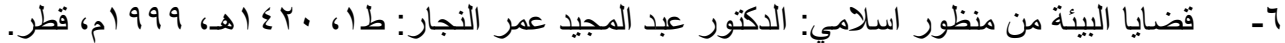

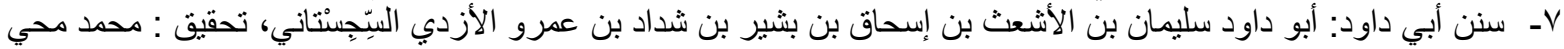

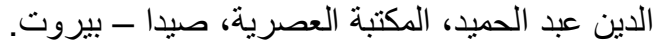

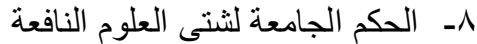

9- صحيح البخاري: محمد بن إسماعيل أبو عبدالله البخاري الجعفي: تحقيق: محمد زهير بن ناصر الناصر، دار طوق النجاة،

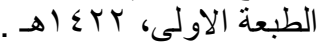

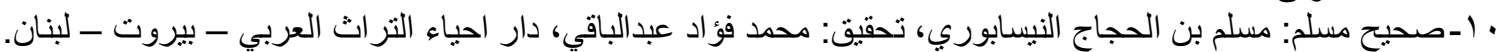

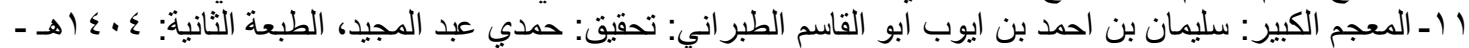

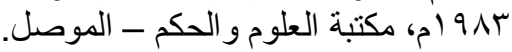
r r ا ـالوجيز في شرح القو اعد الققهية في الثريعة الاسلامية: د. د. عبد الكريم زيدان، مؤسسة الرسالة.

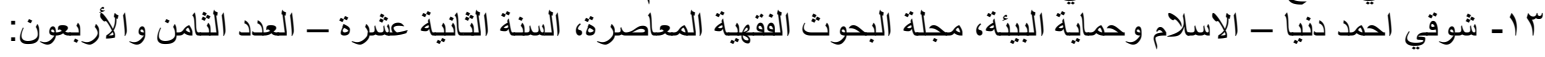
. $1 \leqslant Y \mid$

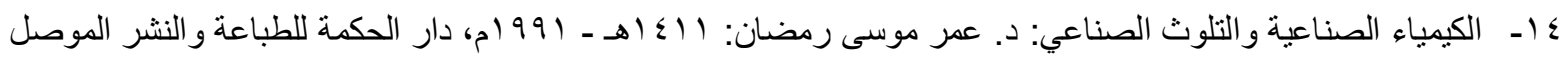

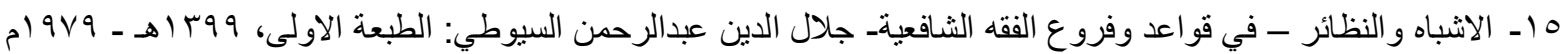
- بيروت - لبنان.

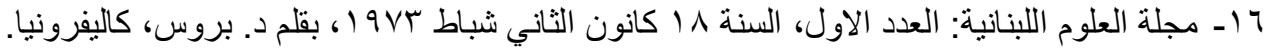

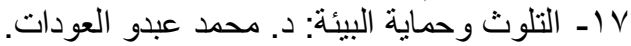

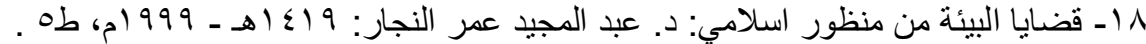

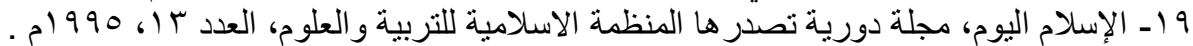

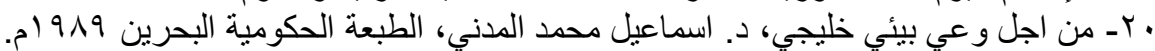

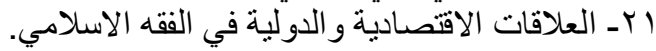

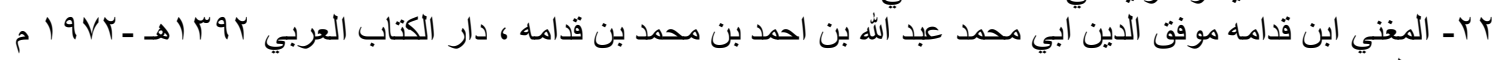

\section{ملخص البحث}

بيروت لبنان.

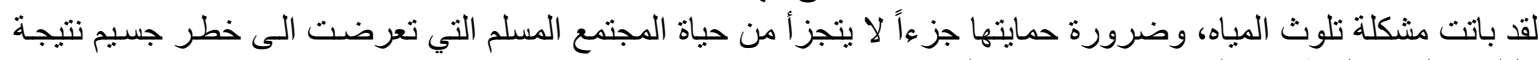

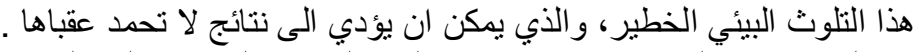

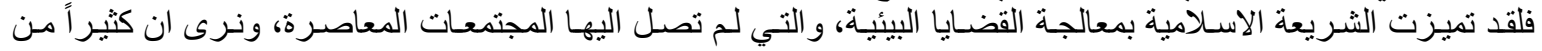

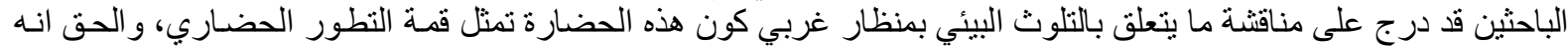

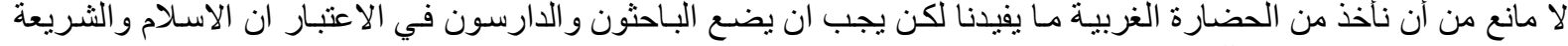

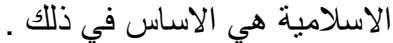

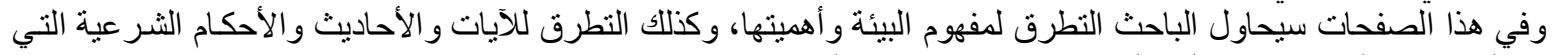

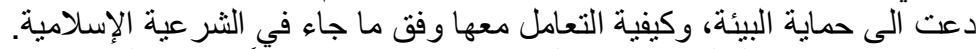

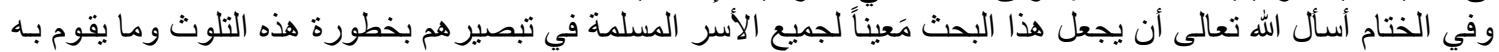

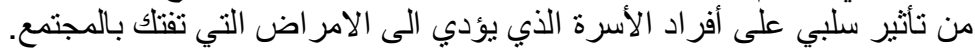




\begin{abstract}
The problems of water pollution, and the necessity of protecting it, have become an integral part of the life of the Muslim community, which has been exposed to a grave danger as a result of this serious environmental pollution, which can lead to unimaginable consequences.

Islamic law has been distinguished by dealing with environmental issues, which contemporary societies have not reached, and we see that many researchers have used to discuss what is related to environmental pollution with a Western perspective, because this civilization represents the summit of civilized development, and the truth is that we do not mind that we take from Western civilization what benefits us But scholars and scholars should bear in mind that Islam and Islamic law are the basis for this.

In these pages, the researcher will try to address the concept of the environment and its importance, as well as the verses, hadiths and legal provisions that called for the protection of the environment, and how to deal with it according to what was stated in Islamic law.

In order to take note of this topic, this research was divided into an introduction and then explaining the topic of the research, its importance and the problem that caused it to be written, and the approach that was followed in writing and dividing it, and then two topics, each of which included a number of demands as follows: -

Keywords: Water pollution, environment, human.
\end{abstract}

